\title{
A estética dos becos em Cora Coralina ou "Um modo diferente de contar velhas estórias"
}

Clovis Carvalho Britto ${ }^{1}$

Goiás, compartimento fechado por todos os lados.

Em volta, o sertão. Dentro da cidade, ruas delimitando classes, orgulho de família, preconceitos sociais, rotina...

Cora Coralina

No protagonismo das margens empreendido pelo projeto criador de Cora Coralina, a vida da cidade é contada a partir das relações travadas no espaço da Casa Velha da Ponte e dos becos; basta consultarmos a ressalva que inseriu na abertura de Poemas dos becos de Goiás ao informar não ser um livro de versos ou poesia, mas "um modo diferente de contar velhas estórias". Essa opção estética pode ser visualizada na intromissão dos gêneros estampada nas peças, muitas das vezes epilíricas ou epiliricodramáticas, fator que contribuiu para que alguns críticos a considerassem mais prosadora do que poeta. Do mesmo modo, estampar a linguagem coloquial e visitar temas até então destinados ao esquecimento poético consistira em um projeto diferente, definido conscientemente pela autora. Daí porque escolheu rever e assinar os autos do passado a partir de um ponto de vista feminino, se assumindo como uma mulher que escrevia para iluminar alguns dos preconceitos de seu tempo e, assim, reorganizar a história oficial. Em Cora observamos o castigo dos cacos amarrados ao pescoço das crianças e a palmatória como forma de disciplina; visualizamos as prostitutas sendo punidas tendo suas cabeças raspadas e sendo obrigadas a capinar as praças; observamos o papel da Igreja e das famílias na tentativa de disciplinar os corpos; vemos o patrimônio imaterial transmitido. Muitos de seus textos trazem temas não contemplados pela historiografia goiana, a exemplo do cotidiano das mulheres, velhos e crianças, os costumes do interior brasileiro, as relações entre mulheres livres e cativas, jovens e velhas, famílias abastadas e famílias anônimas.

Quando Cora Coralina escreveu seu primeiro livro, ainda perdurava a distinção entre história e estória. Conforme destacou Solange Yokozawa, essa distinção hoje nos parece imprópria, visto já ter caído no vulgo que a

\footnotetext{
${ }^{1}$ Doutor em sociologia. Professor da Universidade Federal de Sergipe (UFS), Laranjeiras, SE, Brasil. E-mail: clovisbritto5@hotmail.com
} 
história não passa de uma interpretação do passado e, por isso mesmo, é relativa, ficcional, e "a estória, assumidamente ficcional, muita vez, desvela o passado de uma maneira bem mais 'verdadeira' que as histórias que se querem factuais" (Yokozawa, 2009, p. 200). Cora adotou o termo estória para se referir aos autos do passado por ela recuperados literariamente, opção importante para a compreensão de sua obra na medida em que aparece no título de dois de seus livros (Poemas dos becos de Goiás e estórias mais e Estórias da casa velha da ponte) e se torna elemento estruturante de toda a sua literatura: "pode-se dizer que, em Cora, a estória não quer ser história. A estória, nela, é contra a história. Contra uma história e uma memória coletiva uniformizadoras e agressoras. [...] Coralina parece ter sido a escuta mais eficiente das memórias subterrâneas dos becos de Goiás" (Yokozawa, 2009, p. 200-201).

Essas informações nos permitem observar como a trajetória social de Cora Coralina deixou marcas que definiram os contornos de suas obras. A própria autora constituía um dos "silêncios da história", conforme definiu Michelle Perrot (2005) ao identificar a ausência das mulheres no discurso histórico como se estivessem fora do tempo ou, ao menos, fora do acontecimento. Cora não somente denunciou as ausências ou lutou para que preenchessem esses e outros silêncios como se tornou uma das primeiras mulheres em Goiás que ousaram ser protagonistas de um novo registro, subvertendo os silêncios impostos pela ordem simbólica, não somente os da fala, mas os da expressão gestual e, principalmente, escriturária. Poemas dos becos se tornou uma fonte de mulher, sobre mulheres, nos permitindo compreender como Cora Coralina pensou a sociedade de seu tempo, perseguindo temáticas e estratégias utilizadas para enfrentar os silêncios. Nesse aspecto, concordamos com Kátia Bezerra (2009), quando concluiu que os poemas de Cora questionam paradigmas socioculturais que têm procurado justificar certas configurações constituídas em torno de relações de poder. Situando-a no contexto da literatura escrita por mulheres, verifica o desejo de colocar em circulação experiências diluídas ou tidas como insignificantes no processo de elaboração da memória coletiva, construindo, assim, novos quadros de memória. Demonstra uma genealogia de mulheres inseridas em um tempo que as produziu e que ajudaram, de certa maneira, a perpetuar. Apresenta uma política de memória em que Cora desmantelaria o mito da casa como espaço da harmonia, sacralidade e paz, focalizando variadas violências de acordo com a posição da mulher no tecido familiar, por isso não há como negar a centralidade da mulher na reprodução das relações de poder: a violência não se restringe às figuras masculinas, também está presente nas relações 
entre senhora e escrava, mãe e filhos, filha mais velha e irmãos menores. A poética de Cora Coralina se torna um modo diferente por rememorar situações muitas vezes tensas, especialmente a "tensão entre a situação da mulher com o poder e sua resistência ao poder, na sua tentativa de atribuir novos significados ao passado como uma estratégia necessária ao seu processo de reinvenção" (Bezerra, 2009, p. 89).

Essas situações podem ser evidenciadas na sequência dos poemas de Poemas dos becos. A primeira peça, "Todas as vidas", se torna uma espécie de inventário a inaugurar o eixo de seu projeto. Nela a escritora deixa entreaberta sua opção pela vida das mulheres obscuras, habitantes dos becos físicos e simbólicos, conclamando em cada estrofe muitas das personagens que comparecem em toda a obra: a cabocla velha, a lavadeira do Rio Vermelho, a cozinheira, a mulher do povo, a roceira, a mulher da vida. No segundo poema, "Minha cidade", a poetisa contextualiza o espaço em que situará a maioria dessas mulheres anônimas, apresentando a menina Aninha e se aproximando da mulher velha e esquecida nos becos tristes. Aqui lembramos os ensinamentos de Willi Bolle (2000) quando identificou na obra de Walter Benjamin afinidades entre as estruturas da cidade e os indivíduos que nela vivem, cunhando a categoria memória topográfica, cujo objetivo não seria reconstruir os espaços pelos espaços, mas os conceberia como pontos de referência para captar experiências sociais. Goiás se tornou o espaço privilegiado para o desenvolvimento dessa memória, acionada pelo reencontro com a arquitetura da casa natal, que, por sua vez, margeava o Rio Vermelho e o Beco da Vila Rica.

De acordo com Solange Yokozawa (2009), se o espaço é responsável por comprimir o tempo, os becos compõem o reduto da memória grupal eleito pela escritora. Estreitos e sujos, esquecidos e abandonados, às vezes sem saída, os becos eram o depósito daquilo de que a considerada "boa sociedade" desejava se livrar. Reabilitando a margem, mesmo quando não tematiza tais espaços, Cora Coralina instituiu metaforicamente uma poética dos becos, a exemplo do poema "O palácio dos Arcos", em que opta por narrar a trajetória de um índio carajá, ao invés de descrever a vida dos governadores de província que lá passaram; ou quando trouxe para a sua poética personagens como Lampião, Tiradentes e os judeus errantes. Optou por poetizar a costura dos lugares empreendida pelos boiadeiros a guiar os animais pelo interior em "Evém boiada!", "Trem de gado" e "Pouso de boiadas"; além de realizar uma celebração vegetal em "Oração do milho" e "Poema do milho", demonstrando que, apesar de sua "origem obscura e ascendência pobre" e embora não pertença a "hierarquia tradicional do trigo", exerce um importante papel na história da humanidade. Apesar de em 
apenas três poemas tematizar explicitamente os becos - "Becos de Goiás", "Do Beco da Vila Rica" e "O Beco da Escola" -, poderíamos dizer que toda a sua obra se transformou em uma estética dos becos.

Nesse sentido, nos aproximamos das interpretações de Maria Elaine Kohlsdorf (1996), quando afirma que existiriam variadas manifestações concretas e tipos de espaço arquitetônico e urbanístico (entidades arquitetônicas) que possuiriam em comum uma natureza ao mesmo tempo física e social. O espaço, nesse sentido, não seria rígido e neutro, mas capaz de oferecer restrições e possibilitar a realização de práticas sociais; é por isso que o papel da forma física não é supérfluo: por meio dela se concretiza o desempenho do espaço com relação às expectativas colocadas pelos que o frequentam:

Portanto, a configuração dos espaços possui desempenhos diferenciados relativos a expectativas sociais de diferentes naturezas: possibilitar ou não a acessibilidade entre locais de habitação e trabalho; provocar emoções de beleza ou de insatisfação estética; garantir ou não sombreamento em regiões de insolação excessiva; conduzir ou desorientar o deslocamento das pessoas; permitir ou restringir aglomerações etc. Embora a definição de tais aspirações nem sempre se dê de maneira explícita, ela está presente ao se formularem metas de planejamento urbano e faz com que na verdade, a forma dos lugares seja um fator de realização de todas as práticas sociais, materializando o potencial configurativo das intenções humanas, único porque é capaz de conceder historicidade às formas físicas (Kohlsdorf, 1996, p. 22-23).

Nesse aspecto, é fundamental analisarmos as características de produção e de utilização dos espaços. Podemos detectar possibilidades topoceptivas, ou seja, o comportamento da forma do espaço em resposta às aspirações e identificação dos indivíduos com o ambiente. A cidade se torna uma totalidade composta por uma combinação de partes e, antes de ser uma soma, é uma síntese delas: "Os vínculos entre as diferentes partes entre si, bem como de cada uma com a totalidade, são também de natureza morfológica e se expressam como complementaridade, dependência, segregação, transição, centralidade etc." (Kohlsdorf, 1996, p. 164).

Em Goiás, acreditamos que esses mecanismos simbólicos (as relações entre as partes e o todo, a natureza morfológica expressando segregação, transição e dependência, a influência do espaço na vida mental dos indivíduos) podem ser observados no que Kohlsdorf denominou de conexões: "as 'portas' de entrada e saída dos lugares ou de acesso entre suas partes (conexões internas)" (Kohlsdorf, 1996, p. 165). Na cidade de Goiás essas conexões internas são efetuadas pelos becos e é a partir dos usos e representações desse elemento que Cora elaborou um "retrato" das relações 
sociais de seu tempo e espaço. Em vários poemas e contos a vida da cidade é traduzida a partir da vida nos becos, dos personagens que nele residem e circulam, das relações e reações que provocam como palco e bastidor. $\mathrm{O}$ beco se contrapunha ao largo. Enquanto os largos eram ligados pelas ruas principais, onde viviam as famílias da sociedade reconhecida, os becos eram construções para facilitar o acesso às ruas, geralmente surgindo na confluência dos quintais e funcionando como repositório de tudo o que a "boa sociedade" desejava evitar e, por isso, se tornou o lugar a partir do qual Cora Coralina desvendou a sociedade de seu tempo.

Segundo Gustavo Coelho (1996), na estruturação da cidade de Goiás existem vários elementos que contribuíram para que o espaço se originasse da forma como se encontra atualmente. Tais elementos seriam característicos do modo habitual de organização das cidades no território da metrópole, com influências de origem europeia cristã e árabe, prática incorporada na maioria das cidades coloniais brasileiras. As ruas teriam sido definidas a partir da construção dos edifícios de parede-meia que acompanhavam as ondulações do terreno e formavam uma organização própria, com marcantes influências portuguesas. Como consequências dessa organização encontram-se ruas irregulares interligadas entre si por becos muitas vezes sem saída, geralmente atendendo a parte posterior ou de serviço das residências. Para o autor, o traçado de Goiás, apesar de irregular, mantém certa coerência e, definindo as prováveis influências arquitetônicas, revela que os becos estão mais próximos da arquitetura árabe denominada adarve do que de qualquer elemento ocidental. Citando Goitia, descreve que o adarve seria a negação da rua como valor estrutural, visto que não tem saída, nem continuação, servindo apenas ao interesse privado, compreendido como o conjunto das casas em cujo interior se penetra através de sua passagem.

Os becos serviam para encurtar distâncias, eram espécie de atalhos para as ruas e largos da cidade e originalmente sua função era atender um número restrito de residências como acesso de serviço. Funcionavam urbanisticamente como solução para a existência das extensas quadras e como entrada de serviçais e animais. Os becos ligavam ruas e eram ladeados pelos muros dos quintais e, em algumas situações, possuíam a função de escoamento das águas de rios e córregos. Na maioria das vezes, recebiam o nome dos moradores mais expressivos ou de sua característica mais marcante. As denominações se referiam a questões: geográficas, a exemplo dos becos da Taquara, do Mingú, do Ouro Fino, da Água Férrea e da Cachoeira Grande; de moradores ou instituições às quais dava acesso, como os do Antônio Gomes, do Sócrates, do Teatro, do Quartel, da Matriz, 
da Escola e do Seminário; de seu formato, como o Beco do Cotovelo; ou ainda de lendas e costumes, como os becos do Calabrote e da Vila Rica. Portadores de memórias, os becos foram inventariados e imortalizados por Cora Coralina:

Becos da minha terra,

discriminados e humildes,

lembrando passadas eras...

Beco do Cisco.

Beco do Cotovelo.

Beco do Antônio Gomes.

Beco das Taquaras.

Beco do Seminário.

Bequinho da Escola.

Beco do Ouro Fino.

Beco da Cachoeira Grande.

Beco do Calabrote.

Beco do Mingú.

Beco da Vila Rica... (Coralina, 2001, p. 93).

O arquivo dos becos empreendido por Cora no poema "Becos de Goiás" parte dos espaços mais distantes da Casa Velha da Ponte até chegar ao beco que faz divisa com sua residência - os cinco primeiros, localizados à margem esquerda do Rio Vermelho, os demais, do lado em que foi edificada sua casa natal. Nessa listagem, o beco se torna eco, ressoando sua mensagem por todos os poemas do livro: "amo e canto com ternura todo o errado da minha terra" (Coralina, 2001, p. 93). Pensamento que de certo modo dialoga com as afirmações de Melissa Gomes (2006) quando considerou o beco como uma espécie de liturgia na obra de Cora. Ele representaria outra esfera de poder, onde os anônimos ganhariam um papel de destaque e o livre exercício de poderes. Porém, percebemos que as relações na cidade, mediadas pelos becos, eram conflituosas e os obscuros ganhariam destaque somente na poética coraliniana. Acreditamos que o beco, lugar dos destituídos de fala, pode ser reconhecido mais como forma de resistência do que como de livre exercício de poder, visto que mesmo nesses locais os indivíduos ainda deveriam, de certo modo, obedecer às normas ditadas pela sociedade reconhecida. O que podemos afirmar é que na estética da cidade e na estética de Cora Coralina, esses locais intermediários, relacionais, contribuíram para o estabelecimento de representações, condutas e códigos morais permeando as interações no interior do Centro-Oeste do Brasil durante o século XIX e primeira metade do XX. Por isso mesmo, Goiandira Ortiz de Camargo conclui ser o beco um espaço do intermédio na poesia de Cora Coralina: 
O beco enfeixa significados de transgressão e como espaço também da marginalidade, com um imaginário próprio, quebra o antagonismo entre a casa e a rua, constituindo-se uma espécie de respiradouro da cidade, onde flui o interdito, deposita-se o lixo e ainda serve de passagem para as mulheres de bem transitarem, à luz do dia, de uma casa para outra através do fundo de quintal, sem serem vistas. (...) O beco, então, tem função na vida social da cidade, com uma lógica tácita para a sua ocupação: à noite é lugar de prostitutas em suas atividades, do mal feito, do errado da terra, como escreve a poetisa; durante o dia, é passagem entre os fundos das casas, com trânsito na surdina das mulheres de família. Com essa divisão, o beco mantém a ordem social, com os papéis de cada um que o usa sendo salvaguardados. Porém, o beco põe à vista dos espaços da casa e da rua uma ambigüidade, pois se situa nem em um, nem outra, está de permeio. O beco, assim, mantém um status velado (Camargo, 2009, p. 96).

As representações mentais que os agentes produzem sobre a cidade enquanto localidade produtora de "províncias de significado" e "regiões morais" são importantes mecanismos para a observação das relações travadas em seus cenários e os territórios de sociabilidade se constituem em lócus de sentidos. De acordo com Park (1979), o conceito de região moral é necessário para visualizar as formas com que os agentes se relacionam entre si no ambiente urbano. Os becos podem ser definidos como uma região moral, ou seja, uma região onde prevalecia um código moral divergente. $\mathrm{O}$ local exerceria poder determinante sobre os indivíduos "desviantes", reforçando a sua identidade marginal, identidade definida pela forma como as pessoas desempenham seus papéis em ambientes determinados. Na verdade, conforme descreveu Cora Coralina, os becos eram os lugares por excelência do lixo, dos animais soltos, das brigas, da prostituição nas casas pobres ou ao ar livre, dos mendigos e das pessoas com problemas mentais:

Conto a história dos becos,

dos becos de minha terra, suspeitos... mal afamados

onde família de conceito não passava.

"Lugar de gentinha" - diziam, virando a cara.

De gente do pote d'água.

De gente de pé no chão.

Becos de mulher perdida.

Becos de mulheres da vida.

Renegadas, confinadas

na sombra triste do beco.

Quarto de porta e janela. 
Prostituta anemiada, solitária, hética, engalicada, tossindo, escarrando sangue na umidade suja do beco.

(...)

Mulher-dama. Mulheres-da-vida, perdidas, começavam em boas casas, depois, baixavam pra o beco.

Queriam alegria. Faziam bailaricos.

- Baile Sifilítico - era ele assim chamado.

O delegado-chefe de Polícia - brabeza dava em cima...

Mandava sem dó, na peia.

No dia seguinte, coitadas, cabeça raspada a navalha, obrigadas a capinar o Largo do Chafariz, na frente da Cadeia (Coralina, 2001, p. 94-95).

O beco se tornou lugar de história e de marginalização, especialmente das prostitutas pobres que começavam em boas casas e, depois, baixavam para os becos. Trata-se de temática recorrente em alguns poemas e em dois contos de Estórias da casa velha da ponte, a exemplo de "Miquita" e "Minga, zóio de prata". Miquita era uma filha de lavadeira que foi abandonada pelo marido e, cansada da vida de bater roupas nas pedras, abriu porta no beco, mesmo se o ofício "não dava a ela nem para o aluguel do quarto sujo". Cora descreveu as dificuldades que essas mulheres enfrentavam nos becos, subjugadas pela polícia e pela "macheza dos homens brutais que as espancavam". Também destacou as estratégias utilizadas por algumas mulheres para obter autoridade e prestígio nesses espaços, como as personagens descritas no conto "Minga, zóio de prata", prostitutas no Beco do Calabrote que enfrentavam os homens, caso não seguissem seus preceitos, e, se fosse preciso, diferentemente da situação vivenciada por Miquita, utilizavam de violência física para manter o prestígio e a autoridade naquele espaço.

Inicialmente os becos não abrigavam residências, constituíam apenas lugar de passagem. Todavia, conforme analisamos anteriormente (cf. Britto, 2008), a estagnação econômica em virtude da decadência da mineração, da crise do sistema oligárquico e, posteriormente, da transferência da capital para Goiânia, contribuiu para que a considerada "boa sociedade" parcelasse seus terrenos. No fim de alguns quintais foram construídas pequenas casas, isoladas, entremeadas por muros e portões, espaços que lentamente se transformaram em locais de pessoas e práticas condenadas 
pela moralidade dominante: "os becos que anteriormente serviam como meio de passagem e entrada de serviço, com a construção das residências isoladas ou distanciadas tornaram-se locais por excelência de transgressão, conflito e desordem" (Britto, 2008, p. 141). Não que inexistissem conflitos e transgressões nos outros espaços da cidade, mas nos becos eles obtinham maior visibilidade e recorrência, transformando esses espaços em lugar da permissibilidade, onde algumas práticas, a exemplo dos "bailes sifilíticos", poderiam ser realizadas na clandestinidade. Esse contexto remete às formulações de Norbert Elias e John Scotson (2000), quando avaliaram as relações de poder entre indivíduos que ocupam posições de prestígio, os estabelecidos, e os outsiders, aqueles que se encontram fora da sociedade dominante. A diferença e a desigualdade social seriam as bases das relações entre esses grupos: os primeiros, legitimados pelo poder e distinção a partir do critério da antiguidade, e os demais, caracterizados pelo estigma da associação com o desvio e a violência. Estabelecidos e outsiders permaneceriam afastados e, ao mesmo tempo, unidos pela interdependência. As configurações, oriundas das relações dos indivíduos, resultariam em tensões e interdependências que marcam figurações de adversários ou aliados: "os grupos estabelecidos veem seu poder superior como um sinal de valor humano mais elevado; os grupos outsiders, quando o diferencial de poder é grande e a submissão inelutável, vivenciam afetivamente sua inferioridade de poder como sinal de inferioridade humana" (Elias e Scotson, 2000, p. 28). Ao considerar a comunidade de Goiás nesses moldes, os outsiders também seriam os indivíduos que a poetisa denomina "obscuros", representados pelos habitantes dos becos.

Reconhecer os becos retratados por Cora como regiões morais consiste em concordar que os processos de segregação estabeleceriam distâncias morais que transformam a cidade em um mosaico onde pequenos mundos se tocam, mas não se interpenetram. Para Park, dentro da organização da vida citadina, cada vizinhança, sob influências que tendem a segregar e distribuir populações na cidade, pode assumir o caráter de uma "região moral": "regiões onde prevaleça um código moral divergente, por uma região em que as pessoas que a habitam são dominadas de uma maneira que as pessoas normalmente não o são, por um gosto, por uma paixão, ou por algum interesse que tem suas raízes" (Park, 1979, p. 66). Compreender a sociedade goiana "retratada" na obra de Cora Coralina consiste em reconhecer suas divisões, perspectivas e códigos urbanos: a cidade separada por ruas e largos, expostos, em que foram edificadas as igrejas, os monumentos civis e onde residiam os possuidores de maior capital social, e por becos, locais desprezados, repositórios de lixo, com casas pobres, escondidas no fundo dos quintais, para onde eram 
"empurrados" alguns dos personagens citados na obra da poetisa - pobres, deficientes mentais, negros, desempregados, desenganados, subversivos, obscenos, malandros e prostitutas sem prestígio.

Ao avaliar as cidades interioranas do Brasil como categoria passível de investigação social a partir de sua arquitetura, Roberto DaMatta afirma que o espaço se confunde com a ordem social de forma que "sem entender a sociedade com suas redes de relações sociais e valores, não se pode interpretar como o espaço é concebido. Aliás, nesses sistemas, pode-se dizer que o espaço não existe como uma dimensão social independente e individualizada" (DaMatta, 1997, p. 30). O autor pontua que, muitas vezes, as expressões que designam bairros e ruas exprimem regiões sociais convencionais e locais, indicando antiguidade ou sugerindo segmentação social e econômica. Nesse entendimento, ressalta que a diversidade de espaços e temporalidades convive simultaneamente tornando-se característica da sociedade brasileira. DaMatta descreve espaços considerados problemáticos, como as regiões pobres e de meretrício, afirmando que, geralmente, são regiões periféricas escondidas por tapumes, jamais concebidas como permanentes ou complementares às áreas nobres, mas como locais de transição. Em Goiás, aos que se desviavam do modelo restritivo de comportamento era aplicada a punição que impunha uma relação servil de docilidade e utilidade, necessária à manutenção da hierarquia social e de comando. A poetisa, ao retratar o "espetáculo" da vida nos becos apresenta o destino dos personagens definindo o último ato:

(ÚLTIMO ATO)

Um irmão vicentino comparece.

Traz uma entrada grátis do São Pedro de Alcântara.

Uma passagem de terceira no grande coletivo de São Vicente.

Uma estação permanente de repouso - no aprazível São Miguel.

Cai o pano (Coralina, 2001, p. 95).

Na perspectiva de Cora, somente no ato final as pessoas "de conceito" compareciam oficialmente ao núcleo do "proibido". Os marginalizados não deveriam se manifestar livremente, sob o risco da repressão, e a sociedade só permitia suas saídas do beco para o São Pedro de Alcântara, o São Vicente e o São Miguel - respectivamente, o hospital, o asilo e o cemitério da cidade de Goiás. Dessa forma, poucas opções eram destinadas aos pobres: o confinamento nos becos, nos hospitais e asilos ou a morte, formas eficazes de evitar, silenciar e esconder os "indesejáveis". O que estava à margem não merecia obter visibilidade, e o espaço urbano contribuía para reforçar essa lógica, já que os becos se situam na parte posterior ou na lateral das ruas. Neles não foram construídas igrejas, nem monumentos do poder público, que, em sua 
maioria, localizavam-se nos largos e, esporadicamente, nas ruas principais.

A Igreja também corroborou com a ideia de que não era de bom tom que as mulheres andassem desacompanhadas dos pais ou do marido e, nesse sentido, os becos se tornaram um dos meios utilizados para circularem sem serem vistas. Essa situação é descrita no poema "Do Beco da Vila Rica", portador de dois eixos sociologicamente significativos. O primeiro é a ideia do beco como representativo do conservadorismo e como baliza da cidade: referência e limite. O segundo eixo caracteriza a função dos becos como meio de as mulheres circularem e lugar dos segregados, revelando que a vida do elemento feminino deveria ser "resguardada a sete chaves".

As reflexões da autora ultrapassam a definição dos becos como baliza/ referência da história, retratando-os também como baliza/limite. Inicialmente um limite físico representado pelos muros, portões e pelo lixo que incomodava. Depois um limite social, demonstrado pelas proprietárias dos muros - velhas donas herdeiras da tradição que se protegiam da vida/ morte nos becos através do exercício de repor as telhas destruídas e manter seus portões fechados. Cora Coralina descreve como becos e portões serviam para as mulheres se resguardarem, movimentando-se através dos fundos dos quintais pela entrada de serviço, não integrando a paisagem das ruas e dos largos. Poetizou alguns costumes goianos, a exemplo dos rituais de mandar portador de confiança para solicitar a liberação para visitas, passeios e participação em cerimônias religiosas:

Andar pelas ruas. Atravessar pontes e largos,

as moças daquele tempo eram muito acanhadas.

Tinham vergonha de ser vistas de "todo o mundo"...

Era comum portador com este recado:

- "Vai lá na prima Iaiá, fala pra ela

mandar abrir o portão, depois do almoço,

que vou fazer visita pra ela..."

Costume estabelecido:

Levar buquê de flores.

Dar lembrança, dar recado.

Visitas com aviso prévio.

Mulheres entrarem pelo portão.

Darem voltas, passarem por detrás.

Evitarem as ruas do centro, serem vistas de todo o mundo (Coralina, 2001, p. 105).

Além da faculdade de circularem mediante autorização utilizando becos e portões, a poetisa descreveu a importância do xale e das roupas compridas, como meio de esconder o corpo feminino: "ajudava o velho estatuto/ 
das mulheres se resguardarem,/ embuçadas, disfarçadas./ Olharem na tabuleta./ Entrarem pelo portão./ Passarem por detrás./ Justificando o velho brocardo português:/ 'Mulheres, querem-nas resguardadas a sete chaves'" (Coralina, 2001, p. 106). O poema apresenta uma temática que posteriormente seria aprofundada nos contos da autora: a reclusão das mulheres no espaço da casa e a prática de observarem a rua através das janelas de tabuletas. Muitas casas em Goiás ainda conservam essas janelas que permitem ver sem ser visto, algumas, inclusive, possuindo estruturas laterais em que é possível se assentar, as chamadas "namoradeiras":

Antigamente, as boas casas de Goiás tinham janelas de rótulas como tiveram todas as cidades coloniais deste imenso Brasil. Em Goiás elas sobreviveram por mais de dois séculos. Sobrevivem ainda com velhos costumes domésticos que vão se diluindo através das gerações, ao tempo que as rótulas se modificam sem desaparecer de tudo. [...] Foram elas o documentário mais expressivo da segregação da fêmea dentro da casa senhorial. As de Goiás eram chamadas rótulas de tabuleta, de tabuinhas, de colocação horizontal, grampeadas num pino vertical, móvel, com trincos e tramelinhas laterais, para abrir e fechar à vontade. As paredes onde se encaixavam essas janelas eram de notável espessura como inda se vê em tantas casas. Comportavam internamente, dos lados, assentos lisos ou com almofadas onde as mulheres, mais comodamente, pudessem estar à rotula. Movendo trincos, pinos e tramelinhas era que a gente da casa via o pequeno mundo da cidade e tomava conhecimento de seus moradores. No meu tempo de menina pouco se usava a palavra rótula, só as pessoas mais antigas. Dizíamos 'tabuleta' - estar na tabuleta já sabia estar alguém por dentro, olhando sem ser vista, hábito que perdurou em Goiás até o começo deste século. [...] A observação mais fina e valiosa era de noite, alta noite, com a cidade escura ou enluarada e adormecida (Coralina, 2006, p. 21-22).

A própria arquitetura da cidade contribuía para que as mulheres das casas mais abastadas pudessem observar o que se passava no espaço público através das frestas surgidas no movimentar das janelas. A tabuleta se tornou em estratégia permitida pela dominação masculina para que as mulheres observassem um espaço limitado da vida da cidade e, ao mesmo tempo, constituiu em maneira de controle caso ousassem sair para as ruas, já que também poderiam ser observadas pelas demais moradoras, relembrando, em certa medida, o modelo panóptico de Bentham, a sociedade disciplinar retratada por Michel Foucault em Vigiar e punir (1987). É certo que, quando Cora Coralina publicou seu livro, as mulheres não necessitavam mais estar à tabuleta para observar o espaço público. Todavia, possuíam restrita visibilidade, especialmente no caso das que lutaram por obter uma chance no 
mercado de trabalho - no caso da autora, de se inserir no campo literário. Criada em um tempo em que as mulheres viam o mundo através de pequenas frestas nas janelas, Cora utilizou a escrita para ampliar esse olhar, transformando poeticamente os estreitos becos reservados as mulheres em uma das principais forças de sua avenida literária. Ao trazer as margens para o centro de sua poética contribuiu para criar um espaço alternativo que desloca os binarismos em torno das hierarquias estéticas (erudito x popular, literário x não literário, poesia $\mathrm{x}$ prosa, público $\mathrm{x}$ privado, história $\mathrm{x}$ ficção) e as expectativas do que se convencionou determinar como atividade literária das mulheres (temas e estilos).

A autora se tornou mulher-ponte, ela mesma um elemento conectivo para aproximar os leitores do que até então era desconhecido ou deliberadamente silenciado. Metaforicamente também habitou um estreito beco como mulher, idosa e interiorana. Além de ser um elemento conformador da vida de Goiás, a imagem da rua estreita e geralmente fechada num extremo suscitava a ideia de uma dificuldade quase insuperável, um grande aperto ou situação embaraçosa. A poetisa, encantoada, física e socialmente, por uma sociedade fechada, "que nunca pôde acompanhar o crescimento de sua eudade humana e social, descobre, nos becos, a matéria-prima para a construção da imagem poética de sua própria existência e experiência, bem como da gente pobre com a qual convive e se compromete" (Pesquero-Ramon, 2003, p. 147).

Cora, assim como muitos de seus personagens, enfrentou momentos em que se achou em um "beco sem saída". A solução encontrada, algumas vezes, foi regressar para tomar outro caminho, em outras, saltar os muros estreitos no intuito de deslocar para outros espaços, não se conformando com os lugares tradicionalmente destinados a mulher e, nesse caso, a que almejava fazer da pena um ofício. Isso se torna evidente quando encontramos em seu acervo uma entrevista em que afirma que "o posseiro vivia em um beco" e no seu diário as frases "minha vida entrou por um beco, muito sujo, muito estreito, meio torto, vou caminhando por ele, sem nunca ver o seu fim", "estreita vida de pobre, vou saindo do beco, entrando num beco maior, meu beco de fim de vida" e "fiz de meu beco uma praça, no meio do largo parei vendo a roda da vida rodar, a vida que não levei". A frase sobre o posseiro e a primeira referência de seu diário remetem à ideia do beco como lugar de dificuldades. A segunda frase reforça a primeira, dilatando a interpretação para a vida como um suceder de trajetos, até chegar a um beco maior, cujas estreitezas são reforçadas pelas limitações da velhice. A última imagem remete ao projeto literário da autora, especialmente o fato de ter transformado 
as condições adversas, poetizando outras vidas, e, ampliado, um pouco mais, os espaços reservados a escrita de autoria feminina.

\section{Referências}

BEZERRA, Kátia da Costa (2009). Cora Coralina e o discurso da memória: um retrato da velha Goiás. In: BRITTO, Clovis Carvalho; CURADO, Maria Eugênia; VELLASCO, Marlene (Orgs.). Moinho do tempo: estudos sobre Cora Coralina. Goiânia: Kelps.

BOLLE, Willi (2000). Fisiognomia da metrópole moderna: representação da história em Walter Benjamin. 2. ed. São Paulo: EdUSP.

BRITTO, Clovis Carvalho (2008). Amo e canto com ternura todo o errado da minha terra: literatura e sociedade em Cora Coralina. In: BRITTO, Clovis Carvalho; SANTOS, Robson dos (Orgs.). Escrita e sociedade: estudos de sociologia da literatura. Goiânia: Editora da UCG.

CAMARGO, Goiandira Ortiz de (2009). A escrita poética do espaço em Cora Coralina. Poesia Sempre, Rio de Janeiro, n. 31, p. 85-97.

COELHO, Gustavo Neiva (1996). Goiás: uma reflexão sobre a formação do espaço urbano. Goiânia: Editora UCG.

CORALINA, Cora (2001). Poemas dos becos de Goiás e estórias mais. 20. ed. São Paulo: Global. (2006). Estórias da casa velha da ponte. 13. ed. São Paulo: Global.

DAMATTA, Roberto (1997). A casa \& a rua: espaço, cidadania, mulher e morte no Brasil. 5 ed. Rio de Janeiro: Rocco.

ELIAS, Norbert; SCOTSON, John (2000). Os estabelecidos e os outsiders: sociologia das relações de poder a partir de uma pequena comunidade. Rio de Janeiro: Jorge Zahar. FOUCAULT, Michel (1987). Vigiar e punir: nascimento da prisão. Petrópolis: Vozes. GOMES, Melissa Carvalho (2006). O beco: liturgia na obra de Cora Coralina. In: DENÓFRIO, Darcy França; CAMARGO, Goiandira Ortiz de. Cora Coralina: celebração da volta. Goiânia: Cânone.

KOHLSDORF, Maria Elaine (1996). A apreensão da forma da cidade. Brasília: Editora UnB. PARK, Robert (1979). A cidade: sugestões para a investigação do comportamento humano no meio urbano. In: VELHO, Otávio (org.). O fenômeno urbano. 2. ed. Rio de Janeiro: Zahar.

PERROT, Michelle (2005). As mulheres ou os silêncios da história. Bauru: EDUSC. PESQUERO-RAMON, Saturnino (2003). Cora Coralina: o mito de Aninha. Goiânia: Editora da UFG; Editora da UCG.

YOKOZAWA, Solange Fiúza Cardoso (2009). Confissões de Aninha e memória dos becos. In: BRITTO, Clovis Carvalho; CURADO, Maria Eugênia; VELLASCO, Marlene (Orgs.). Moinho do tempo: estudos sobre Cora Coralina. Goiânia: Kelps.

Recebido em dezembro de 2012.

Aprovado em abril de 2013. 


\section{resumo/abstract}

\section{A estética dos becos em Cora Coralina ou "Um modo diferente de contar velhas estórias"}

Clovis Carvalho Britto

Este artigo analisa as interconexões entre literatura, memória e cidade a partir da obra de Cora Coralina (1889-1985). Instituindo uma memória topográfica, a escritora goiana elegeu os becos como espaço privilegiado para a tessitura de sua estética. A partir dessa chave interpretativa, observamos as relações sociais no interior brasileiro nos séculos XIX e XX construídas sob um olhar que reabilita os entrelugares. Em vários poemas e contos a vida da cidade é traduzida a partir da vida nos becos, dos personagens que nele residem e circulam, das relações e reações que provocam como palco e bastidor. Pretendemos, desse modo, analisar as estratégias utilizadas pela autora para retratar e criticar a realidade de seu tempo considerando os becos como metáfora e metonímia de sua cidade. A partir de uma inserção marginal, especialmente devido a preconceitos com relação à sua idade e condição feminina, Cora desenvolveu uma estética dos becos em que mulheres e outras minorias, nem sempre numéricas, tornaram-se centro.

Palavras-chave: Cora Coralina, memória, cidade, becos.

\section{The aesthetics of the alleys in Cora Coralina or "A different way to tell old stories"}

\section{Clovis Carvalho Britto}

This article examines the interconnections between literature, memory and the city in the work of Cora Coralina (1889-1985). From a topographic memory, Coralina elected the alleys as a privileged space for her work's aesthetics. In this interpretive key, she observed social relations within Brazil in the nineteenth and twentieth centuries from a point of view that rehabilitates the margins. In several poems and tales, the city life is translated from life in the alleys, the characters who reside there, and relationships and reactions that it causes. We intend, therefore, to analyze the strategies used by the author to portray and criticize the reality of their time considering the alleys as metaphor and metonymy of your city. From a marginal insertion, especially due to prejudices regarding their age and condition of women, Cora developed an aesthetic of alleys where women and other minorities, not always numeric, become the center.

Keywords: Cora Coralina, memory, city, alleys. 